\title{
Qualitative and Quantitative Analysis of Changes in Saliva and Subjective Oral Dryness in Patients with Thyroid Disorders
}

\author{
Zhahid Hassan ${ }^{1}$, Afreen Nadaf' ${ }^{2}$, Sonia Gupta ${ }^{3}$ \\ 'DM, Endocrinology, Health services, Kashmir, ${ }^{2}$ Department Of Oral Pathology, GDC\&H, Srinagar, ${ }^{3}$ Tutor, Department Of Oral Pathology GDC\&H, Srinagar.
}

\section{Abstract}

Background: The association of salivary function with numerous systemic illnesses has been stated by various researches. There is a strong relationship of salivary function with common illnesses like diabetes, oral submucous fibrosis, and asthma. Thyroid dysfunction are one of the most common endocrine disorders worldwide. Aims and objective: To determine the qualitative and quantitative changes in the salivary function in patients with thyroid dysfunction. Subjects and Methods: A cross-sectional study was carried out on 40 subjects, including 20 thyroid disorders patients and 20 control subjects. Unstimulated and stimulated salivary flow rates, $\mathrm{pH}$, and buffering capacity of the whole saliva were determined as well as subjective oral dryness in the study subjects. Results: In the present study, a statistically significant decrease in salivary parameters such as buffering capacity and flow rates was seen. Subjective oral dryness was observed in affected patients. Conclusion: In the present study, a correlation between thyroid dysfunction and salivary gland function was observed in patients with thyroid disorders.

Keywords: Hyperthyroidism, hypothyroidism, buffering capacity, Saliva.

Corresponding Author: Dr. Sonia Gupta, Tutor, Dept. of Oral Pathology, GDC\&H, Srinagar.

Received: June 2019

Accepted: June 2019

\section{Introduction}

Saliva contains various components like sodium, potassium, calcium, magnesium, bicarbonate, phosphates, immunoglobulins, proteins, enzymes, mucins, nitrogenous products such as urea and ammonia. Bicarbonates, phosphates and urea maintain the $\mathrm{pH}$ (5.3-7.8) and buffering capacity of saliva. Proteins and mucins help to cleanse, aggregate and/or attach oral microorganisms and contribute to dental plaque metabolism. Calcium, phosphate and proteins work together as antisolubility factor which control demineralization and remineralization. Immunoglobulins, proteins and enzymes contribute to antimicrobial action to the saliva. ${ }^{[1]}$ Saliva plays an essential role in maintaining the health of oral cavity by various host defense functions like homeostatic processes, lubrication, antimicrobial activity and control of demineralization /remineralization of teeth. ${ }^{[2]}$ Various studies have described the subjective and objective functional losses that happen in persons who lack the ability to produce adequate volumes of saliva. These functional losses are dry mouth (xerostomia), difficulty with swallowing of food (dysphagia), and an increased susceptibility for opportunistic infections of the oral cavity. ${ }^{[3]}$ Unstimulated saliva are produced predominantly by the submandibular glands and minor salivary glands as well as considered as an indicator of the basal production and thus provide more protection to the oral cavity. ${ }^{[4]}$ The factors which affect unstimulated salivary flow rate include degree of hydration, body position, exposure to light, previous stimulation, circadian rhythms, and drugs. ${ }^{[5]}$ Stimulated saliva predominantly secreted by the parotid gland and provide protection during mastication as well as helps in deglutition. ${ }^{[4,6]}$ Nature of stimulus, vomiting, smoking, gland size, gag reflex, olfaction, unilateral stimulation, and food intake are the factors which affect the stimulated saliva. ${ }^{[7]}$ Any variation in the quality and quantity of saliva will give rise to interruption in the protective functions of the saliva. ${ }^{[8]}$ The most common thyroid disorders are hypothyroidism and hyperthyroidism which disturb multiorgan systems in the human body. Thyroid diseases are most common endocrine disorders worldwide. Various researches have suggested that about 42 million people in India have suffered from thyroid disorders. ${ }^{[9]}$ The aim of the present study was to determine the qualitative and quantitative changes in the salivary function in patients with thyroid dysfunction.

\section{Subjects and Methods}

A study was conducted on 40 subjects, comprising of 20 thyroid disorders patients who visited the OPD at Khyber hospital, Srinagar and 20 subjects were selected as a control. The study subjects who had non-thyroid disorders at the general OPD were taken as a control after complete check up by a physician. An informed consent was obtained from the subjects. Patient with a history of tobacco use, pregnant women, the subjects who had undergone 
radiotherapy, patients who had taken medication that affect salivary secretion and the subjects with a history of systemic disorders were excluded from the study.

\section{Analysis of saliva:}

The study subjects were educated not to eat, drink, smoke, chew, or perform oral hygiene for 60 minutes before collection of saliva. The saliva was collected at the same time of the day (between 8 and $10 \mathrm{am}$ ) for each patient so as to eliminate bias due to diurnal variation. ${ }^{[10]}$

\section{Salivary flow rates:}

The collection of unstimulated saliva was obtained from the patient first by asking them to sit quietly, with the head bent down and mouth open to allow the saliva to drop from the lower lip into a sterile container (the draining method). This was then followed by collection of stimulated whole saliva by using unflavored paraffin wax on the basis of standardized collection procedure defined by Tenovuo and Lagerlöf. After collection of saliva, the flow rates of unstimulated and stimulated saliva were determined. ${ }^{[11]}$

\section{Estimation of pH and buffering capacity:}

The stimulated whole saliva was then estimated for the $\mathrm{pH}$ and buffering capacity. The $\mathrm{pH}$ of the saliva was then measured by a handheld digital manual $\mathrm{pH}$ meter (Hanna) and the buffering capacity of the saliva were determined by adding $3 \mathrm{ml}$ of $5 \mathrm{mmol} / \mathrm{l} \mathrm{HCl}$ to $1 \mathrm{ml}$ of saliva. The mixture was dynamically shaken and then centrifuged for $1 \mathrm{~min}$ and allowed to stand for $10 \mathrm{~min}$ when the final $\mathrm{pH}$ was measured with the help of manual $\mathrm{pH}$ meter. ${ }^{[6]}$

\section{Oral Dryness:}

Subjective oral dryness symptoms were noted using a short questionnaire taken from the study accompanied by Farsi in 2007. The responses of the participants were evaluated on the basis of criteria of given by Farsi, wherein the subjects who answered at least one question were considered as positive for subjective oral dryness complaint. ${ }^{[12]}$

\section{Results}

The data was analysed by using statistical software (SPSS version 19.0). Mean, standard deviation and proportion were calculated for cases and controls. A probability value (p) of $\leq 0.05$ was considered to be statistically significance.

In the present study, out of 20 newly diagnosed cases of thyroid disorders, $65 \%(\mathrm{n}=13)$ were females and $35(\mathrm{n}=$ 07) were males. Out of the 20 age and gender- matched controls, $70(n=14)$ were females and $30 \%(n=06)$ were males.

The mean \pm SD USFR in the case group was $0.236 \pm 0.128 \mathrm{~mL} / \mathrm{min}$, which was significantly lower $(\mathrm{P}<$ 0.001 ) than that of control group with mean \pm SD USFR of $0.482 \pm 0.179 \mathrm{~mL} / \mathrm{min}$ (Table 1). On the basis of Tenovuo and Lagerlöf criteria11, 40\% ( $\mathrm{n}=08)$ of cases had low USFR $(0.1-0.25 \mathrm{ml} / \mathrm{min})$ and $10 \%(\mathrm{n}=02)$ cases had hyposalivation $(<0.1 \mathrm{~mL} / \mathrm{min})$. In the control group, $13.33 \%$ $(\mathrm{n}=03)$ had low USFR and there were no subject with hyposalivation.

The mean \pm SD SSFR in the case group was found to be $1.362 \pm 0.584 \mathrm{~mL} / \mathrm{min}$, which was significantly lesser $(\mathrm{P}<$ 0.001 ) than control group with mean \pm SD SSFR of $1.782 \pm 0.241 \mathrm{~mL} / \mathrm{min}$ (Table 1). On the basis of Ericsson and Hardwick criteria13 $25 \%(\mathrm{n}=05)$ of cases had low SSFR $(<1 \mathrm{~mL} / \mathrm{min})$ and $15 \%(\mathrm{n}=03)$ cases had hyposalivation $(<0.7 \mathrm{~mL} / \mathrm{min})$. In the control group, there were no study subjects with hyposalivation or low SSFR.

\begin{tabular}{|c|c|c|c|c|}
\hline & & & & \\
\hline \multirow{3}{*}{ USFR $(\mathrm{ml} / \mathrm{min})$} & & & & \multirow{3}{*}{$<0.001$} \\
\hline & Cases & 20 & $0.236 \pm 0.128$ & \\
\hline & control & 20 & $0.482 \pm 0.179$ & \\
\hline \multirow[t]{2}{*}{ SSFR (ml/min) } & Cases & 20 & $1.362 \pm 0.584$ & \multirow[b]{2}{*}{$<0.001$} \\
\hline & control & 20 & $1.782 \pm 0.241$ & \\
\hline \multirow[t]{2}{*}{$\mathrm{pH}$} & Cases & 20 & $6.972 \pm 0.3522$ & \multirow[b]{2}{*}{$<0.001$} \\
\hline & control & 20 & $6.861 \pm 0.3781$ & \\
\hline \multirow{2}{*}{$\begin{array}{l}\text { Buffering } \\
\text { capacity }\end{array}$} & Cases & 20 & $5.3846 \pm 1.1805$ & \multirow[b]{2}{*}{0.001} \\
\hline & control & 20 & $6.0172 \pm 0.482$ & \\
\hline
\end{tabular}

The mean \pm SD salivary $\mathrm{pH}$ of cases and controls were $6.972 \pm 0.3522$ and $6.861 \pm 0$. The $\mathrm{p}$-value was found to statistically significant $(\mathrm{P}<0.001)$ [Table 1$]$. In the present study, $40 \%(\mathrm{n}=08)$ of cases felt that the saliva present in their mouth appeared to be too little but only $10 \%(\mathrm{n}=02)$ among the controls felt the same. A statistically significant difference was found between the groups $(\mathrm{P}=0.001)$.

The assessment of questionnaire responses between cases and control are found in Table 2 with a statistically significant difference. About $65 \%(\mathrm{n}=13)$ of subjects among the case group and $20.0 \%(n=04)$ of subject in the control group answered as positive (responded at least one question in affirmative) for subjective oral dryness complaints.

Table 2: Assessment of questionnaire responses between cases and controls

\begin{tabular}{|l|l|l|l|l|l|}
\hline \multirow{2}{*}{ Question } & Cases & \multicolumn{2}{|l|}{ Control } & \multirow{2}{*}{ P-value } \\
\cline { 2 - 5 } & Yes & No & Yes & No & 0.001 \\
\hline 1 & 09 & 11 & 02 & 18 & 0.00 \\
& $(45 \%)$ & $(55 \%)$ & $(10 \%)$ & $(90 \%)$ & \\
\hline 2 & 07 & 13 & 04 & 16 & $<0.001$ \\
& $(35 \%)$ & $(65 \%)$ & $(20 \%)$ & $(80 \%)$ & \\
\hline 3 & 05 & 15 & 02 & 18 & 0.001 \\
& $(25 \%)$ & $(75 \%)$ & $(10 \%)$ & $(90 \%)$ & \\
\hline 4 & 08 & 12 & 05 & 15 & 0.002 \\
& $(40 \%)$ & $(60 \%)$ & $(25 \%)$ & $(75 \%)$ & \\
\hline
\end{tabular}

\section{Discussion}

The association of salivary function with numerous systemic illnesses has been stated by various researches. There is a strong relationship of salivary function with common illnesses like diabetes, oral submucous fibrosis, and asthma. ${ }^{[14-16]}$ Thyroid dysfunction are one of the most common endocrine disorders worldwide. Muralidharan et al 
2013 in their study evaluated only stimulated whole mouth saliva flow rate in thyroid disorder patients. ${ }^{[17]}$ Warfvinge et al in 1992 establish a relationship using unstimulated whole sialometry and parotid scintigraphy only in hypothyroid patients. ${ }^{[18]}$ A study done by Naik et al in 2018 stated the unstimulated and stimulated salivary flow rates in hyperthyroid and hypothyroid patients. ${ }^{[19]}$ In our study, we have determined unstimulated salivary flow rate (USFR) and stimulated salivary flow rate (SSFR) in thyroid disorders patients.

The present study suggests that a thyroid disorders are more commonly seen in females than males. These findings are in agreement with the recent literature. ${ }^{[19-21]}$

The mean USFR in the case group was within the normal range quoted in literature while that of the control group was slightly higher than normal. During the time of collection of saliva, slight movement of the tongue and cheeks alter the true unstimulated saliva, thereby signifying attention when we interpret the USFR results. ${ }^{[19,22]}$

The mean SSFR in the case and the control groups were within the normal limits for normal population. These proportions are slightly lower in our case group as compared to the study done by Muralidharan et al. ${ }^{[17]}$

The mean $\mathrm{pH}$ values of both the cases and controls were in the normal range. This is in agreement with the study done by Muralidharan et al and Naik et al. ${ }^{[17,19]}$

The mean buffering capacity of saliva among the controls was higher than that of cases. The low buffering capacity of saliva is associated with a reduced salivary flow and particularly increased risk for caries. These findings were in accordance with the study done by Muralidharan et al and Naik et al. ${ }^{[17,19]}$

The questionnaire obtained from the study carried out by Farsi in 2007 was used to determine the perception of subjective oral dryness among the subjects. ${ }^{[12]}$ The present study results suggest that oral dryness was more among the thyroid disorder patients than the healthy controls. These findings were similar to study done by Naik et al. ${ }^{[19]}$

\section{Conclusion}

The present study determines a correlation of thyroid dysfunction and salivary gland function in thyroid disorders patients. In the present study, a statistically significant decreases in salivary parameters such as buffering capacity and flow rates. Hence, a subject with thyroid disorders would be subjected to regular dental checkups and proper preventive measures should be followed to provide adequate oral health and hygiene status to the patient.

\section{References}

1. De Almeida Pdel V, Grégio AM, Machado MA, de Lima AA, Azevedo LR. Saliva composition and functions: A comprehensive review. J Contemp Dent Pract 2008; 9:72 80.

2. Prasanthi B, Kannan N, Patil R. Effect of diuretics on salivary flow, composition and oral health status: A clinico-biochemical study. Ann Med Health Sci Res 2014; 4: 549-53.

3. Amerongen AV, Veerman EC. Saliva - The defender of the oral cavity. Oral Dis 2002; 8: 12-22.

4. Navazesh M, Christensen CM. A comparison of whole mouth resting and stimulated salivary measurement procedures. J Dent Res 1982; 61:1158-1162.

5. Dawes C. Physiological factors affecting salivary flow rate, oral sugar clearance, and the sensation of dry mouth in man. J Dent Res 1987; 66:648-653.

6. Edgar WM. Saliva: Its secretion, composition and functions. Br Dent J 1992; 172:305-312.

7. Dawes C. Factors influencing salivary flow rate and composition. In: Edgar M, Dawes C, O'Mullane D, editors. Saliva and Oral Health. 4th ed. London: Stephen Hancocks Limited; 2012.

8. Llena-Puy C. The rôle of saliva in maintaining oral health and as an aid to diagnosis. Med Oral Patol Oral Cir Bucal 2006; 11:E449-E455.

9. Unnikrishnan AG, Menon UV. Thyroid disorders in India: An epidemiological perspective. Indian J Endocrinol Metab 2011;15:S78S81.

10. Dawes C. Circadian rhythms in human salivary flow rate and composition. J Physiol 1972; 220:529-545.

11. Tenovuo J, Lagerlöf F. Saliva. In: Thylstrup A, Fejerskov O. Textbook of Clinical Cariology. 2nd ed. Copenhagen, Denmark. Munksgaard; 1994.

12. Farsi NM. Signs of oral dryness in relation to salivary flow rate, $\mathrm{pH}$, buffering capacity and dry mouth complaints. BMC Oral Health 2007; $7: 15$.

13. Ericsson Y, Hardwick L. Individual diagnosis, prognosis and counselling for caries prevention. Caries Res 1978; 12 Suppl 1:94-102.

14. Lasisi TJ, Fasanmade AA. Salivary flow and composition in diabetic and non-diabetic subjects. Niger J Physiol Sci 2012; 27:79-82.

15. Rooban T, Mishra G, Elizabeth J, Ranganathan K, Saraswathi TR. Effect of habitual arecanut chewing on resting whole mouth salivary flow rate and $\mathrm{pH}$. Indian J Med Sci 2006; 60:95-105.

16. Lenander-Lumikari M, Laurikainen K, Kuusisto P, Vilja P. Stimulated salivary flow rate and composition in asthmatic and non- asthmatic adults. Arch Oral Biol 1998; 43:151-6.

17. Muralidharan D, Fareed N, Pradeep PV, Margabandhu S, Ramalingam $\mathrm{K}$, Ajith Kumar BV et al. Qualitative and quantitative changes in saliva among patients with thyroid dysfunction prior to and following the treatment of the dysfunction. Oral Surg Oral Med Oral Pathol Oral Radiol 2013; 115:617-623.

18. Warfvinge G, Larsson A, Henricsson V, Ericsson UB, Hansen B, Manthorpe $\mathrm{R}$ et al. Salivary gland involvement in autoimmune thyroiditis, with special reference to the degree of association with Sjögren's syndrome. Oral Surg Oral Med Oral Pathol 1992; 74:288-293.

19. Naik MM and Vassandacoumara V. Qualitative and quantitative salivary changes and subjective oral dryness among patients with thyroid dysfunction. Ind J Dent Res 2018; 29(1): 16-21.

20. Bauer M, Glenn T, Pilhatsch M, Pfennig A, Whybrow PC. Gender differences in thyroid system function: Relevance to bipolar disorder and its treatment. Bipolar Disord 2014; 16:58-71.

21. Canaris GJ, Manowitz NR, Mayor G, Ridgway EC. The Colorado thyroid disease prevalence study. Arch Intern Med 2000; 160:526-34.

22. Percival RS, Challacombe SJ, Marsh PD. Flow rates of resting whole and stimulated parotid saliva in relation to age and gender. J Dent Res 1994; 73:1416-20.

Copyright: (C) the author(s), publisher. Asian Journal of Medical Research is an Official Publication of "Society for Health Care \& Research Development". It is an open-access article distributed under the terms of the Creative Commons Attribution Non-Commercial License, which permits unrestricted non-commercial use, distribution, and reproduction in any medium, provided the original work is properly cited. 
Copyright: ( ) the author(s), 2019. It is an open-access article distributed under the terms of the Creative Commons Attribution License (CC BY 4.0), which permits authors to retain ownership of the copyright for their content, and allow anyone to download, reuse, reprint, modify, distribute and/or copy the content as long as the original authors and source are cited.

How to cite this article: Hassan Z, Nadaf A, Gupta S. Qualitative and Quantitative Analysis of Changes in Saliva and Subjective Oral Dryness in Patients with Thyroid Disorders. Asian J. Med. Res. 2019;8(3):DE04-DE07.

DOI: dx.doi.org/10.21276/ajmr.2019.8.3.DE2 